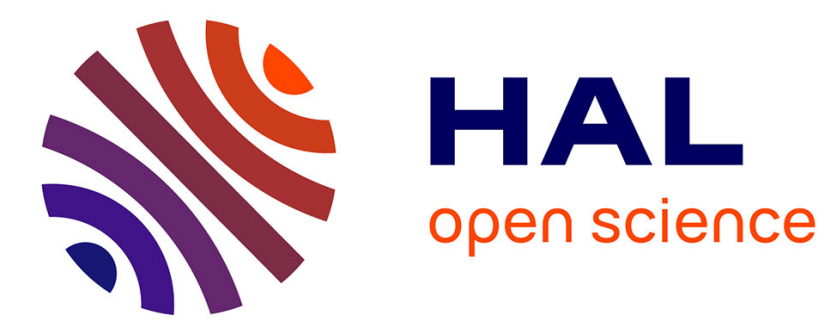

\title{
Influence of Fermi energy equalization on crystal nucleation in glass melts
}

Robert F. Tournier

\section{To cite this version:}

Robert F. Tournier. Influence of Fermi energy equalization on crystal nucleation in glass melts. Journal of Alloys and Compounds, 2009, 483 (1-2), pp.94-96. 10.1016/J.jallcom.2008.08.102 . hal-02937168

\section{HAL Id: hal-02937168 \\ https://hal.science/hal-02937168}

Submitted on 12 Sep 2020

HAL is a multi-disciplinary open access archive for the deposit and dissemination of scientific research documents, whether they are published or not. The documents may come from teaching and research institutions in France or abroad, or from public or private research centers.
L'archive ouverte pluridisciplinaire HAL, est destinée au dépôt et à la diffusion de documents scientifiques de niveau recherche, publiés ou non, émanant des établissements d'enseignement et de recherche français ou étrangers, des laboratoires publics ou privés. 


\title{
Influence of Fermi energy equalization on crystal nucleation in glass melts
}

\author{
Robert F. Tournier, \\ *Centre National de la Recherche Scientifique, Consortium de Recherches pour l'Emergence \\ de Technologies Avancées, B.P. 166, 38042-
}

\footnotetext{
Corresponding author. Tel.: +33476881211; fax: +33476881280 ; e-mail:

Robert.Tournier@grenoble.cnrs.fr
} 


\begin{abstract}
The energy saving produced by the equalization of Fermi energies of a crystal and a melt has been associated to the crystal formation in undercooled melts to determine the new homogeneous-nucleation critical-temperature $\mathrm{T}_{2}$ and the new nucleation critical barrier as a function of the temperature T. Small unmelted clusters act as nuclei by reducing the critical energy barrier and the nucleation times; the glass transition temperature $\mathrm{T}_{\mathrm{g}}$ occurs near $\mathrm{T}=\mathrm{T}_{2}$. The temperature dependence of the specific heat difference of the undercooled melt with the
\end{abstract}

Keywords: Amorphisation; Crystal growth; metals.

Pacs numbers: 81.10.Aj; 64.70.Pf

\title{
1- Introduction
}

Transformations liquid-solid are accompanied by changes of the conduction electron number per volume unit. The equalization of Fermi energies of a solid particle and of its melt produces an unknown energy saving $\varepsilon_{\mathrm{v}}$ equal to a fraction $\varepsilon_{l s}$ of the fusion heat per volume unit. All crystal nucleation models have been built to describe the crystallization of all types of materials without taking account of $\varepsilon_{v}$ in metallic alloys [1-3]. This contribution has been recently added to the Gibbs free energy change associated to a crystal formation in 38 liquid elements; tiny intrinsic crystals can survive above the melting temperature and act as heterogeneous nuclei for crystallization above a homogeneous-nucleation critical-temperature $\mathrm{T}_{2}$; the thermal variation of $\varepsilon_{l s}$ is an even function of $\theta$ having a maximum value $\varepsilon_{l s 0}=0.217$ for $\mathrm{T}=\mathrm{T}_{\mathrm{m}}$ in agreement with the thermodynamic equilibrium conditions and a zero value when the free volume of melts disappears [4-6].

The same analysis is applied to metallic glass-forming melts because large values of $\varepsilon_{l s 0}$ induced by large Fermi energy changes are expected due to weak localization of conduction electrons in the melts $[7,9]$.

\section{2- The crystal nucleation model completed}

When the Gibbs free energy change for a crystal formation takes account of the energy saving $-\varepsilon_{\mathrm{v}}$, the relations (1) and (2) are obtained for 38 liquid elements[4-6]:

$$
\varepsilon_{\mathrm{v}}=\varepsilon_{l s} \frac{\Delta H_{m}}{V_{m}} \quad \text { where } \quad \varepsilon_{l s}=\varepsilon_{l s 0}\left(1-\frac{\theta^{2}}{\theta_{0}^{2}}\right)
$$

The new critical energy barrier $\frac{\Delta G_{2 l s}^{*}}{k T}$ and the new critical radius $R_{2 l s}(\theta)$ are equal to:

$$
\frac{\Delta G_{2 l s}^{*}}{k_{B} T}=\frac{16 \pi \Delta S_{m} \alpha_{2 l s}^{3}}{3 N_{A} k_{B}\left(\theta-\varepsilon_{l s}\right)^{2}(1+\theta)} ; R_{2 l s}=-2 \frac{\alpha_{2 l s}}{\theta-\varepsilon_{1 s}}\left(\frac{V_{m}}{N_{A}}\right)^{1 / 3} \text { where } \quad \alpha_{2 l s} \Delta S_{m}^{1 / 3}=\left(\frac{12 R}{432 \pi}\right)^{1 / 3} \times\left(\operatorname{Ln} K_{1 s}\right)^{1 / 3}\left(1+\varepsilon_{l s}\right)
$$

$\Delta \mathrm{S}_{\mathrm{m}}$ being the fusion entropy per mole, $\mathrm{V}_{\mathrm{m}}$ the molar volume, $\mathrm{N}_{\mathrm{A}}$ the Avogadro number, $\Delta \mathrm{H}_{\mathrm{m}}$ the fusion enthalpy per mole, $\operatorname{Ln}\left[\mathrm{K}_{\mathrm{ls}}(\mathrm{T})\right] \leq 90 \pm 2$ or $\left(\mathrm{K}_{\mathrm{ls}} \leq 10^{39 \pm 1} \mathrm{~m}^{-3} \cdot \mathrm{s}^{-1}\right), \theta_{0}=\left(T_{0}-T_{m}\right) / T_{m}, \mathrm{~T}_{0}$ the disappearance temperature of the free volume and of $\varepsilon_{\mathrm{ls}}$; tiny crystals can survive above $\mathrm{T}_{\mathrm{m}}$ up 
to $\theta=\varepsilon_{l s}$. Their radius cannot grow because the critical barrier ${ }_{\Delta G_{2 l s}^{*}}^{*}$ is diverging when $\theta$ tends to $\theta=\varepsilon_{l s}$ and is in fact reduced to a value smaller than the critical radius of liquid -droplet homogeneous - nucleation [6]; these nano-size crystals of radius $\mathrm{R}$ govern the crystallization for $0>\theta>\theta_{2}$ because the homogeneous nucleation energy barrier $\frac{\Delta G_{2 l s}^{*}}{k T}$ is reduced by the free energy saving $\frac{\Delta G_{n m}}{k T}$ due to the previous solidification of these intrinsic crystals of radius $R_{n m}$. The contribution $\frac{\Delta G_{n m}}{k T}$ to the effective critical energy barrier is calculated using (3) [10]; its thermal variation is determined by the temperature dependence of the critical radius $R_{21 s} ; R_{n m}$ is temperature independent as long as the nucleation time is not attained:

$\frac{\Delta G_{n m}}{\Delta G_{2 l s}^{*}(\theta)}=3\left(\frac{R_{n m}}{R_{2 l s}}\right)^{2}-2\left(\frac{R_{n m}}{R_{2 l s}}\right)^{3}$

Assuming that the intrinsic nuclei are numerous, the nucleation rate $\mathrm{J} \mathrm{m}^{-3} \mathrm{~s}^{-1}$ is given by (4) $[1-3,17]$ :

$\operatorname{Ln}\left(J . \mathrm{v} . t_{s n}\right)=\operatorname{Ln}\left(K_{l s} \mathrm{v} \cdot t_{s n}\right)-\frac{\Delta G_{2 l s}^{*}}{k T}+\frac{\Delta G_{n m}^{*}}{k T}$

$\mathbf{J}$ attains a maximum equal to 1 for $\theta_{2}=\left(\varepsilon_{2 l s}-2\right) / 3$ when the nucleation is homogeneous; $\theta_{2}$ does not depend on $\operatorname{Ln}\left[\mathrm{K}_{\mathrm{ls}}(\theta)\right]$ values. The steady-state nucleation time $\mathrm{t}_{\mathrm{sn}}$ necessary to observe the first crystallization induced by a heterogeneous nucleation at a temperature $\mathrm{T}$ is given by J.v.t $\mathrm{t}_{\mathrm{sn}}$ $=1$ where $\mathrm{J}>>1$.

\section{3- The glass transition}

The $\varepsilon_{l s 0}$ values of glass-forming melts are deduced from the measured $\theta_{g}=\left(T_{g}-T_{m}\right) / 3$ using $\varepsilon_{l s}=3 \theta_{2}+2$ where $\theta_{2}=\theta_{g}$ or $T_{2}=T_{m}\left[\varepsilon_{l s}\left(T_{2}\right)+1\right] / 3$ where $\mathrm{T}_{2}=\mathrm{T}_{\mathrm{g}}$. The $\mathrm{K}_{\mathrm{ls}}$ value is equal to a constant $\mathrm{A} \eta_{0}$ weakly varying with $\mathrm{T}$ divided by the viscosity $\eta$ given by a Vogel-Fulcher Tammann (VFT) equation [10]. It is assumed that the free volume disappears at $\mathrm{T}=\mathrm{T}_{0}$ or $\theta=\theta_{0}$ as a consequence of the Doolittle relation between the viscosity and the free volume [10]; $\mathrm{D}^{*}$ is the glass fragility parameter. $\mathrm{Ln}\left(\mathrm{K}_{\mathrm{ls}}\right)$ is chosen equal to :

$$
\operatorname{Ln}\left(K_{l s}\right)=\operatorname{Ln}\left(\frac{A \eta_{0}}{\eta}\right)=\operatorname{LnA}-\frac{D^{*} T_{0}}{\left(T-T_{0}\right)}
$$

LnA is of the order of 90 and will be slightly varied. The values of $T_{m}, T_{g}, \theta_{g}, T_{0}, \theta_{0}, D^{*}$ and $\varepsilon_{\mathrm{ls} 0}^{1}$ of some undercooled melts are given in Table 1. 
Table 1

The melting temperature $T_{m}$, the glass transition $T_{g}$, The VFT temperature $T_{0 l}$ of the undercooled melt, the glass fragility $D^{*}, \theta_{g}=\left(T_{g}-T_{m}\right) / T_{m}, \theta_{0 l}=\left(T_{o l}-T_{m}\right) / T_{m}$, the calculated nose temperature $T_{n}$, the electronic energy saving coefficient $\varepsilon_{l s 0}^{l}$ at $T=T_{m}$ associated to a crystal formation are given for various melts with references. $N^{\circ} 1=P d_{43} C u_{27} N i_{10} P_{20}(A=84)$; $N^{\circ} 2=Z_{41.2} \operatorname{Ti}_{13.8} C u_{12.5} N_{10} B e_{22.5}(A=84) ; N^{\circ} 3=M_{6}{ }_{65} Y_{10} C u_{25}(A=86) ; N^{\circ} 4=\operatorname{Nickel}(A=$ 90).

\begin{tabular}{|l|l|l|l|l|l|l|l|}
\hline $\mathrm{N}^{\circ}$ & Ref. & $\mathrm{T}_{\mathrm{m}}(\mathrm{K})$ & $\mathrm{T}_{\mathrm{g}}(\mathrm{K})$ & $\mathrm{T}_{01}(\mathrm{~K})$ & $\mathrm{D}^{*}$ & $\mathrm{~T}_{\mathrm{n}}(\mathrm{K})$ & $\varepsilon_{1 \mathrm{~s} 0}^{1}$ \\
\hline 1 & {$[12,20]$} & 802 & 585 & 452.3 & 9.14 & 726 & 1.93 \\
\hline 2 & {$[14,21]$} & 937 & 625 & 412.5 & 18.5 & 800 & 1.55 \\
\hline 3 & {$[22]$} & 739 & 420 & 260 & 22.1 & 565 & 1.27 \\
& & 739 & 400 & 260 & 22.1 & 563 & 1.25 \\
\hline 4 & {$[15]$} & 1725 & 425 & 575 & 0 & 575 & 0.217 \\
\hline
\end{tabular}

The glass transition is accompanied by a free volume freezing and a thermal variation change of $\varepsilon_{\mathrm{v}}$ below $\theta_{\mathrm{g}}$ as compared to that of the undercooled liquid; $\varepsilon_{1 \mathrm{~s}}^{1}=\varepsilon_{l s 0}^{l}\left[1-\left(\theta / \theta_{0 l}\right)^{2}\right]$ will be changed in $\varepsilon_{\mathrm{ls}}^{\mathrm{g}}=\varepsilon_{l s 0}^{g}\left[1-\left(\theta / \theta_{0 g}\right)^{2}\right]$ with $\varepsilon_{\mathrm{ls}}^{1}\left(\theta_{g}\right)=\varepsilon_{\mathrm{ls}}^{g}\left(\theta_{g}\right), \varepsilon_{\mathrm{ls}}^{1}$ and $\varepsilon_{\mathrm{ls}}^{\mathrm{g}}$ respectively being the electronic energy saving coefficients in the undercooled liquid and in the glass; $\theta_{0 l}$ and $\theta_{0 g}$ respectively corresponding to the liquid and the glass VFT temperatures. The specific heat jump $\Delta C_{p}=C_{p}^{l}-C_{p}^{g}$ per unit volume can be calculated from the derivative of $\left(\varepsilon_{\mathrm{v}}^{1}-\varepsilon_{\mathrm{v}}^{\mathrm{g}}\right)$ :

$\Delta C_{p}=C_{p}^{l}-C_{p}^{g}=\frac{d\left(\varepsilon_{\mathrm{v}}^{1}-\varepsilon_{\mathrm{v}}^{\mathrm{g}}\right)}{d T}=\frac{2 \Delta H_{m} \theta}{T_{m} V_{m}}\left[\varepsilon_{l s 0}^{g} \theta_{0 g}^{-2}-\varepsilon_{l s 0}^{l} \theta_{0 l}^{-2}\right]$

it is a linear function of the temperature in agreement with measurements on $\mathrm{Pd}_{43} \mathrm{Cu}_{27} \mathrm{Ni}_{10} \mathrm{P}_{20}$ alloys [12]. 


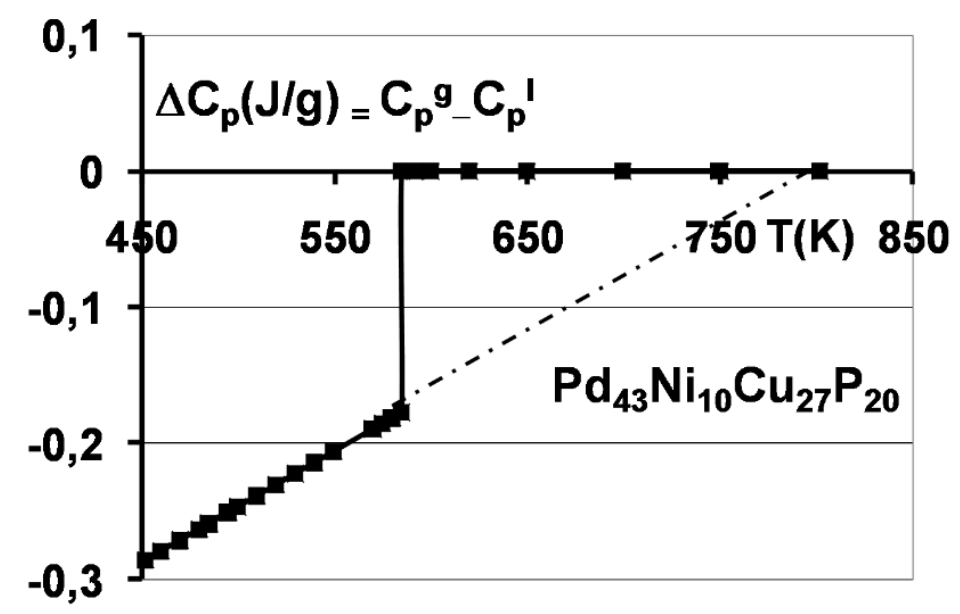

Figure 1:

The calculated difference $\Delta C_{p}(T)$ between the glass specific heat $C_{p g}$ and the specific heat $C_{p l}$ of $\mathrm{Pd}_{43} \mathrm{Cu}_{27} \mathrm{Ni}_{10} \mathrm{P}_{20}$ undercooled melt extrapolated from $T_{g}=585 \mathrm{~K}$ down to $T_{o l}=452.3 \mathrm{~K}$.

The parameters $\varepsilon_{l s 0}^{g}=1.726$ and $\theta_{0 g}=-0.484$ are determined by using the specific heat jump of $13 \mathrm{~J} / \mathrm{mole}(0.177 \mathrm{~J} / \mathrm{g})$ at $\mathrm{T}=\mathrm{T}_{\mathrm{g}}$ and by assuming that the glass transition does not produce any discontinuity of $\varepsilon_{\mathrm{ls}}$. The jump $\Delta C_{p}$ is represented in Figure 1 as a function of $\theta$ only for $\theta_{0 l}<\theta<0$ because $\varepsilon_{\mathrm{ls}}^{1}$ stays equal to zero below $\theta=\theta_{01}$. The theoretical thermal variation of $\Delta C_{p}$ given by (7) is in very good agreement with experimental measurements on $\mathrm{Pd}_{43} \mathrm{Cu}_{27} \mathrm{Ni}_{10} \mathrm{P}_{20}$ alloys:

$$
\Delta C_{p}(J / g)=C_{p}^{l}-C_{p}^{g}=0.644-0.000803^{*} T(7)
$$

A residual contribution linearly varying with the temperature below $\theta_{\mathrm{g}}$ down to $\theta_{01}$ is reproduced. The model also predicts a change of the VFT temperature of $\mathrm{Pd}-\mathrm{Ni}-\mathrm{Cu}-\mathrm{P}$ glass from $452.3 \mathrm{~K}\left(\theta_{01}=-0.436\right)$ to $413.8 \mathrm{~K}\left(\theta_{0 g}=-0.484\right)$. A viscosity weakening below the glass transition has been already observed in some glasses $[10,22]$.

The glass transition has been defined by $\mathrm{T}_{\mathrm{g}}=\mathrm{T}_{2}$ without special validation. The temperature $\theta_{2}$ could be a little larger or smaller than $\theta_{\mathrm{g}}$ instead of being equal. In the first case, the energy barrier increases and then decreases very quickly and could make the crystallization much easier; then, the glass transition has to be very close to $\theta_{2}$. In the second case, the VFT temperature $T_{0 \mathrm{~g}}$ is decreased as compared to the initial value corresponding to $\theta_{\mathrm{g}}=\theta_{2}$ and then, the viscosity weakening is amplified. Measurements of viscosity below the glass transition and of the specific heat jump are necessary to evaluate any difference in this relation. The temperature $\mathrm{T}_{0 \mathrm{~g}}$ has not to be too low as compared to $\mathrm{T}_{01}$ because the viscosity would be too much weakened below $\mathrm{T}_{\mathrm{g}}$; the relation $\theta_{2} \cong \theta_{g}$ seems to be more compatible with few results already known [10, 22]. 


\section{4- Temperature-Time-Transformation diagrams}

The calculation of the nucleation time $t$ of the first crystallization has to take account not only of the steady-state nucleation time $t_{\mathrm{sn}}$ but also of the time-lag $\tau_{\mathrm{ns}}$ in transient nucleation [10] with:

$$
\begin{array}{ll}
t=t_{s n}+\frac{\pi^{2}}{6} \tau_{n s} \text { when } t \gg>\frac{\pi^{2}}{6} \tau_{n s} & \text { (8) } \\
J \tau^{n s}=\frac{a_{0}^{*} N}{2 \pi \Gamma(z)} \exp \left(-\frac{\Delta G_{e f f}^{*}}{k T}\right) \quad \text { where } & \Gamma(z)=\left(\frac{1}{3 \pi k T} \frac{\Delta G_{2 l s}^{*}}{j_{c}^{2}}\right)^{1 / 2},
\end{array}
$$

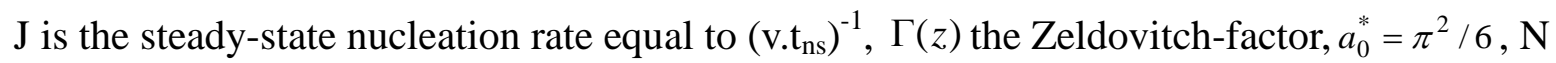
the atom number per volume unit, $\mathrm{j}_{\mathrm{c}}$ the atom number in the critical sphere. The first crystallization occurs when $J=\left(v \cdot t_{\mathrm{sn}}\right)^{-1} ; \mathrm{t}_{\mathrm{sn}}$ can be calculated from (4) only when the sample volume $\mathrm{v}$ is known. The critical energy barrier is obtained by using (2) and the values of $\varepsilon_{\mathrm{ls}}^{1}$ as a function of $\theta ; t_{\mathrm{sn}}$ is deduced from (4) with $\ln \left(\mathrm{K}_{\mathrm{ls}}\right)$ given by (5). The various parameters used in these calculations are given in Table 1 . The time-lag is easily obtained when $t_{\mathrm{sn}}$ has been determined. The influence of $\tau_{\mathrm{ns}}$ is very important near the glass transition. The calculated nose temperatures $\mathrm{T}_{\mathrm{n}}$ of $\mathrm{Mg}_{65} \mathrm{Y}_{10} \mathrm{Cu}_{25}, \mathrm{Zr}_{41.2} \mathrm{Ti}_{13.8} \mathrm{Cu}_{12.5} \mathrm{Ni}_{10} \mathrm{Be}_{22.5}, \mathrm{Pd}_{43} \mathrm{Cu}_{27} \mathrm{Ni}_{10} \mathrm{P}_{20}$ and Nickel melts are given in Table 1 in agreement with measurements.

\section{$\mathrm{Pd}_{43} \mathrm{Cu}_{27} \mathrm{Ni}_{10} \mathrm{P}_{20}$}

The isothermal- crystallization first-event of several $\mathrm{mg}$ samples have been studied by processing in $\mathrm{B}_{2} \mathrm{O}_{3}[13,16,20,23]$; it is not reproducible above $700 \mathrm{~K}$ because the contribution $\Delta \mathrm{G}_{\mathrm{nm}}$ is varying from sample to sample. The calculated TTT curves are reproducible below $700 \mathrm{~K}$ when the nucleation time at the nose temperature is strongly varying; it is due to the large contribution of the time-lag $\tau_{\mathrm{ns}}$ at lower temperatures.

$\mathrm{Zr}_{41.2} \mathrm{Ti}_{13.8} \mathrm{Cu}_{12.5} \mathrm{Ni}_{10} \mathrm{Be}_{22.5}$

The TTT diagram has been studied using a containerless electrostatic levitation technique [14]. The nose temperature and the nose time are $800 \mathrm{~K}$ and $70 \mathrm{~s}$, respectively. Two TTT curves have been calculated by using the parameters given in Table $1, A=86$ and 90 . They have respectively nose temperatures of $800 \mathrm{~K}$ and $745 \mathrm{~K}$.

\section{$\mathrm{Mg}_{65} \mathrm{Y}_{10} \mathrm{Cu}_{25}$}

The experimental TTT diagrams are easily reproduced by using sample volumes varying from $1.2 \mathrm{E}-9$ to $4 \mathrm{E}-10 \mathrm{~m}^{3}, \mathrm{~A}=86,400<\mathrm{T}_{\mathrm{g}}<420 \mathrm{~K}$. The nose temperature is varying from 563 to $565 \mathrm{~K}[22]$.

\section{Nickel}

The liquid elements have $\theta_{2}=-2 / 3$ or $\mathrm{T}_{2}=0.333 \mathrm{~T}_{\mathrm{m}}$; the nickel glass transition $\mathrm{T}_{\mathrm{g}}$ after a cooling rate of $3 \mathrm{E}+10 \mathrm{~K} / \mathrm{s}$ is equal to $0.246^{*} \mathrm{~T}_{\mathrm{m}}$ [15]. The glass transition is smaller than $0.33^{*} \mathrm{~T}_{\mathrm{m}}$ because the measurement time is too long compared to the cooling time. The TTT diagram calculated with $\mathrm{LnK}_{1 \mathrm{~s}}=90$ has a nose at $\mathrm{T}_{\mathrm{n}}=0.333 \mathrm{~T}_{\mathrm{m}}$. 


\section{Conclusion}

The glass transition $\mathrm{T}_{\mathrm{g}}$ occurs near the new homogeneous-nucleation criticaltemperature $\mathrm{T}_{2}$ equal to $T_{2}=T_{m}\left[\varepsilon_{l s}\left(T_{2}\right)+1\right] / 3$; values of $\varepsilon_{l s 0}$ are larger than 1 in bulk glasses [4$6]$. It produces a free volume freezing $[10,18]$ and an increase of the electronic energy saving $\varepsilon_{\mathrm{v}}$ below $\mathrm{T}_{\mathrm{g}}$ without step; $\varepsilon_{\mathrm{ls}}^{1}$ is continuously changed in $\varepsilon_{\mathrm{ls}}^{\mathrm{g}}, \varepsilon_{\mathrm{ls}}^{1}$ and $\varepsilon_{\mathrm{ls}}^{\mathrm{g}}$ respectively being the electronic energy saving coefficients in the undercooled liquid and in the glass. The specific heat jump ${ }_{\Delta C_{p}}=C_{p}^{l}-C_{p}^{g}$ at $\mathrm{T}=\mathrm{T}_{\mathrm{g}}$ of the $\mathrm{Pd}_{43} \mathrm{Cu}_{27} \mathrm{Ni}_{10} \mathrm{P}_{20}$ undercooled liquid is used to calculate $\left(\frac{d\left(\varepsilon_{\mathrm{v}}^{1}-\varepsilon_{\mathrm{v}}^{\mathrm{g}}\right)}{d T}\right)_{T=T_{g}}$ that is a linear function of $\mathrm{T}$ and the parameters involved in $\varepsilon_{\mathrm{ls}}^{\mathrm{g}}$. The theoretical thermal variation of $\Delta C_{p}$ is then in very good agreement with the experimental measurements of $\Delta C_{p}=C_{p}^{l}-C_{p}^{g}[12]$.

Large values of $\varepsilon_{l s 0}$ have been used to predict the nose temperature of TTT diagrams of Nickel, $\mathrm{Zr}_{41.2} \mathrm{Ti}_{13.8} \mathrm{Cu}_{12.5} \mathrm{Ni}_{10} \mathrm{Be}_{22.5}, \mathrm{Pd}_{43} \mathrm{Cu}_{27} \mathrm{Ni}_{10} \mathrm{P}_{20}, \mathrm{Mg}_{65} \mathrm{Y}_{10} \mathrm{Cu}_{25}$ [11-15]. They explain the critical cooling and heating rate variations, the magnitude order changes of the crystallization time by the existence of intrinsic heterogeneous nuclei which are not melted. Their presence is known since many years in spite of applying relatively large overheating [24-27].

\section{Acknowledgments:}

The author thanks J. Friedel, J.L. Soubeyroux, E. Beaugnon for helpful comments.

\section{References:}

[1] D. Turnbull, J. Chem. Phys. 20 (1952) 411

[2] K.F. Kelton, Sol. Stat.Phys. 45 (1991) 75

[3] B. Vinet, L. Magnusson, H. Fredriksson and P.J. Desré, J. of Coll. and Interf. Sc. 255

(2002) 363-374

[4] R. F. Tournier, Physica.B, Condensed Matter, 392 (2007) 79

[5] R.F. Tournier, Progress in Light Metals, Aerospace Mat. Supercond. Part 4, (2007) 1827 (

Ed: Y. Lu, P. Zhang, C. Jiang and Y. Han, Trans Tech Publ.);

[6] R.F. Tournier, EPM 2006, the $V^{\text {th }}$ Int. Symp. Electromagn. Proc. Mat. (Ed: S. Taniguchi, Iron Steel Inst. Japan, 2006) 561

[7] N.F. Mott, Adv. Phys. 16 (1967) 49

[8] O. Haruyama, H.M. Kimura, N. Nishiyama,A. Inoue, J. Arai, Mat. Trans., 43 (2002) 1931

[9] A. Inoue, Acta Mater. 48 (2000) 279

[10] I. Gutzow and J. Schmelzer, The vitreous state, Ch 2.4, 6.2, 6.3 (Ed. Springer, 1995)

[11] J. Schroers, W. L. Johnson and R. Busch, Appl. Phys. Lett. 77 (2000) 1158

[12] I-R. Lu, G. Wilde, G.P. Görler and R. Willnecker, J. of Non-Cryst. Solids 250-252 (1999) 577

[13] J. Schroers, Y. Wu, R. Busch and W. L. Johnson, Acta Mater. 49 (2001) 2773

[14] S. Mukherjee, Z. Zhou, J. Schroers. W.L. Johnson, W.K. Rhim, Appl. Phys. Lett. 84 (2004) 5010 
[15] Z.P. Lu, C.T. Liu, Acta Mat. 50 (2002) 3501

[16] T. D. Shen and R. B. Schwarz, Appl. Phys. Lett. 88 (2006) 091903

[17] D. Turnbull and J.C. Fisher, J. Chem. Phys. 17 (1949) 71

[18] I.-R. Lu, G.P. Görler, R. Willnecker, Appl. Phys. Lett. 80 (2002) 4534

[19] N. Nishiyama and A. Inoue, Mat.Trans. JIM, 40 (1999) 64; 37 (1996) 1531

[20] T.A. Waniuk, R. Busch, A. Masuhr, W.L. Johnson, Acta Mater. 46 (1998) 5229

[21] R. Busch, W. Liu, W.L. Johnson, J. Appl. Phys. 83 (1998) 4134

[22] Z. P. Lu, C.T. Liu, Acta Mater. 50 (2002) 3501

[23] N. Nishiyama and A. Inoue, Appl. Phys. Lett, 80 (2002) 568; Mat. Trans. 43 (2002) 1913

[24] C. Fan and A. Inoue, Appl. Phys. Lett. 75 (1999) 3644

[25] V. Manov, P. Popel, E. Brook-Levinson, V. Molokanov, M. Calvo-Dahlborg, U. Dahlborg, V. Sidorov, L. Son, Yu. Tarakanov, Mat. Sc. Eng., A 304-306 (2001) 54

[26] P. Rudolph, H. J. Koh, N. Shäfer, T. Fukuda, J. Cryst. Growth, 166 (1996) 578

[27] C.C. Hays, W.L. Johnson, J. Non-Cryst. Sol. 250-252 (1999) 596. 